\title{
Prevalence, indications and neonatal complications of caesarean deliveries in Cameroon: a systematic review and meta- analysis
}

Tsi Njim ${ }^{1 *}$ (D) Bayee Swiri Tanyitiku² and Clarence Mbanga ${ }^{3}$

\begin{abstract}
Background: The trend of increasing caesarean deliveries in developed countries over the past three decades is now being observed in sub-Saharan African. This rise might be associated with an increase in the complications that could arise from this surgical intervention. We therefore sought to assess the prevalence, indications and complications of caesarean deliveries in Cameroon.
\end{abstract}

Methods: We systematically searched online databases: Medline; Global Health and the CINAHL from 01st January 1966 to 25th July 2019. We reviewed published cohort studies, retrospective register analysis and cross-sectional studies that described cohorts of pregnant women presenting at delivery facilities in Cameroon; and included those that had an estimate of the proportion of women who delivered by caesarean sections.

Results: There were 126 articles initially identified by the search and 88 articles were retained after removal of duplicates. After screening of the titles and abstracts, and full text review, we identified 16 articles describing 22 cohorts of women presenting for delivery in health facilities in Cameroon. The overall estimate for the prevalence of caesarean deliveries was 9.9\% (95\% Cl: 7.4, 12.8\%, $\left.\mathrm{I}^{2}=99.68 \%, \mathrm{X}^{2}=315.9, p<0.001\right)$. The prevalence of caesarean deliveries increased progressively from 3.4\% (95\% Cl: 2.2, 4.8\%) before the year 2000, to 9.8\% (95\% Cl: 7.4, 12.8\%) between 2000 and 2009 and 14.7\% (95\% Cl: 8.8, 21.7\%) from 2010 to 2019. The three commonest indications for caesarean deliveries were: cephalopelvic disproportion (27.5\%; 95\% Cl: 17.5, 38.7\%); previous caesarean deliveries (13.2\%; 95\% Cl: 7.4, 20.3\%) and foetal distress (11.2\%; 95\% Cl: 4.8, 19.5\%). Neonates who were born by caesarean delivery were more likely to have neonatal asphyxia when compared with neonates born from vaginal deliveries (OR: 6.5; 95\% Cl: 2.5, 16.5).

Conclusion: The rates of caesarean deliveries in Cameroon falls just within the recommended $10-15 \%$ range proposed by the World Health Organisation but have however been increasing progressively in the past decades. There is a strong need to assess the various indications of caesarean deliveries in Cameroon in order to curb its associated complications.

Keywords: Caesarean deliveries, Caesarean sections, Neonatal asphyxia, Cameroon

\footnotetext{
* Correspondence: tsinjim@gmail.com

${ }^{1}$ Health and Human Development (2HD) Research Group, Douala, Littoral region, Cameroon

Full list of author information is available at the end of the article
}

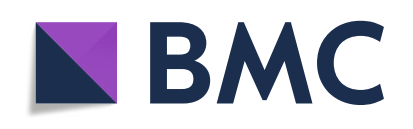

(- The Author(s). 2020 Open Access This article is licensed under a Creative Commons Attribution 4.0 International License, which permits use, sharing, adaptation, distribution and reproduction in any medium or format, as long as you give appropriate credit to the original author(s) and the source, provide a link to the Creative Commons licence, and indicate if changes were made. The images or other third party material in this article are included in the article's Creative Commons licence, unless indicated otherwise in a credit line to the material. If material is not included in the article's Creative Commons licence and your intended use is not permitted by statutory regulation or exceeds the permitted use, you will need to obtain permission directly from the copyright holder. To view a copy of this licence, visit http://creativecommons.org/licenses/by/4.0/. The Creative Commons Public Domain Dedication waiver (http://creativecommons.org/publicdomain/zero/1.0/) applies to the data made available in this article, unless otherwise stated in a credit line to the data. 


\section{Background}

A caesarean delivery is a surgical intervention which consists of making an incision on the walls of the abdomen and the uterus, for delivery of the baby. It is one of the most commonly performed surgical interventions globally [1], and it is primarily performed as a live-saving procedure when the health of the mother or baby is deemed to be at significant risk, if a vaginal delivery is attempted [2, 3].

The World Health Organization (WHO) recommends caesarean delivery rates of $10-15 \%[1,4,5]$. This is based on evidence from several reports suggesting that at $10-15 \%$, caesarean deliveries are associated with a significant reduction of maternal and perinatal morbidity and mortality $[6,7]$. At higher rates, the benefits associated with caesarean deliveries fade away $[8,9]$, and as is the case with most other surgical procedures, exposes both mother and baby to significant short and long term risks and complications $[1,8,9]$.

This is worrisome considering the rise in the rates of caesarean deliveries over the past three decades $[3,10]$. This rise is highest in high- and middle-income countries, with countries in Western Europe, North America and South America now registering caesarean delivery rates of over $30 \%$ [3, 10-12]. This increase in caesarean delivery rates could partly be explained by the rising number of caesarean sections performed at the request of the mothers due to a perceived relative safety, in both developed and developing countries $[3,13]$.

An increase in caesarean delivery rates, similar to the trend observed above has been noted in Sub-Saharan Africa, raising serious concern from several authors [3, 14]. These concerns are due to the lack of comprehensive and appropriate obstetric care in health facilities, needed to manage the potential risks and complications that could result from a caesarean delivery, in some of the rural settings in these countries [15-17]. In such settings, estimating the prevalence and indications of caesarean deliveries could help policymakers with strategy implementations. A comprehensive knowledge on the general and setting-specific complications associated with caesarean deliveries could help clinicians anticipate the possible outcomes in both mother and child and guide them in revising or establishing new management plans.

We therefore sought to carry out this review to systematically assess the prevalence, indications and complications of caesarean deliveries in Cameroon.

\section{Methods}

\section{Setting}

Cameroon is a multi-ethnic country made up of ten geopolitical regions with 24 million inhabitants (Additional file 1) [18]. As of $2017,55.5 \%$ of the population were living in an urban area [19]. The ten regions (in order of the regions with the most populated cities) are: Littoral; Centre; Far North; North; West; North west; Adamawa; East; South west and South regions [20] (Additional file 1).

\section{Study design and eligibility criteria}

This review was conducted following a predesigned protocol which was e-registered in the PROSPERO database (Registration number: CRD42019144543); and reported according to the Preferred Reporting Items for Systematic Reviews and Meta-Analyses (PRISMA) guidelines. We systematically searched online databases including Medline; Global Health and the CINAHL databases using the following keywords, search terms and phrases: ("caesarean section", "caesarean delivery" or "operative delivery" and "Cameroon"); coupled with their associated medical subject headings (MeSH). The search started from 01st January 1966 to 25th July 2019. The search strategy used was produced by an information specialist (Additional file 2). We reviewed published cohort studies, retrospective register analysis and crosssectional studies that included pregnant women presenting at delivery facilities in Cameroon; and which provided an estimate of the prevalence of caesarean deliveries (Table 1). A grey literature search was also carried out by assessing book chapters and documents from organizations such as WHO, and the United States Centers for Disease Control and Prevention (CDC). We excluded studies that did not report primary data such as letters, systematic reviews and commentaries.

\section{Data management}

Articles returned by the search were retrieved electronically and saved to EndNote version $\times 8$ software, which was used to screen and remove duplicates. The titles and abstracts of the remaining articles were screened against the above inclusion and exclusion criteria for eligibility independently by two reviewers - TN \& BST. Disagreements were handled by discussion and consensus between the two reviewers.

The full texts of eligible articles were downloaded for data extraction. For articles with missing information necessary for the review, the authors of the article were contacted by email requesting the information.

A tool designed on Microsoft Excel 2010 prior to the search and pretested by the principal investigator - TN, was used for data extraction.

\section{Data items and extraction}

The data extraction tool was used by the two aforementioned independent reviewers to extract the following general information from each article that satisfied the inclusion criteria: Last name of first author; date of 
Table 1 PICOS strategy for inclusion criteria of studies into review

\begin{tabular}{ll}
\hline PICOS strategy & Inclusion criteria \\
\hline P-population & Pregnant women who present for deliveries across hospitals in Cameroon \\
I-intervention/Exposure & Caesarean delivery \\
C-comparison & Women who have vaginal deliveries or instrumental vaginal deliveries \\
O-outcome(s) & Neonatal complications: asphyxia and stillbirth \\
S-study design & Cross-sectional and cohort studies \\
\hline
\end{tabular}

publication; region in which the study took place; proportion of participants who gave birth through caesarean deliveries; various indications of caesarean deliveries; the study design; age range of participants; sample size; duration of data collection, time of participant recruitment and various maternal and neonatal complications of caesarean deliveries.

\section{Assessment of methodological quality and risk of bias}

The two independent reviewers used the Quality Assessment Tool for Observational Cohort and Cross-Sectional Studies of the National Health Institute/National Heart, Lung, and Blood Institute to assess for methodological quality (Additional file 3). Studies were deemed of good quality if $>70 \%$ of the applicable criteria were attained in the quality assessment tool, fair quality if $\geq 40-70 \%$ of the applicable criteria were attained in the quality assessment tool and poor quality if $<40 \%$ of the applicable criteria were attained in the quality assessment tool.

\section{Data synthesis and analysis}

A meta-analysis was performed to obtain an overall pooled measure of the proportion of caesarean deliveries in Cameroon with a subgroup analyses done to obtain pooled effects for different groups: regions, time periods (before 2000; between 2000 and 2009 and from 2010 to 2019), settings (rural, semi-urban and urban) and types of health facilities (primary, secondary and tertiary).

The various indications of caesarean deliveries were described, and a meta-analysis performed for each indication if at least two studies listed the indication in their results. A meta-analysis was also performed to assess the relationship between the complications and caesarean deliveries using the odds ratio as the measure of the estimate. Meta-analyses and subgroup analyses were only performed if at least two studies reported the relevant outcome or subgroup.

\section{Assessment of heterogeneity}

Due to the variability of the different study settings and study designs; a random effects meta-analysis model was used for interpretation over fixed-effects models. The $x^{2}$ test for heterogeneity and the $\mathrm{I}^{2}$ statistic were used to assess the degree of heterogeneity.

\section{Results}

There were 123 articles initially identified by the search (Fig. 1). Eighty-eight articles were retained after removal of duplicates. Three articles were further identified from the references of the articles retained from the search. After screening of the titles and abstracts, 24 articles were retained for full text review. The full text review identified 16 articles that reported on the prevalence of caesarean deliveries in Cameroon.

Three of the studies could be broken up into two separate cohorts of women each [3,21,22], while one of the studies (the Demographic Health survey analysis) was broken up into four cohorts of women [23]. The other studies each reported on a single cohort of women [22, 24-35]. In total, 22 cohorts of women were included in the review. These cohorts included a total of 269,006 women presenting for deliveries in health facilities. The characteristics of the cohorts of pregnant women included in the review are summarised in Table 2.

Two of the cohorts were from the North west region $[24,31]$, two were from the Littoral region [21, 33], eight from the Centre region $[21,25-30,32]$, three from the South west region $[3,34]$, three from the Far north region $[22,35]$ and the Demographic Health survey analysis did not specify regions [23]. All the studies used a cross-sectional design except Ngowa et al and Foumane et al $[29,30]$ which utilised a cohort design and Tebeu et al [35] used an additional case-control design to assess the complications of caesarean deliveries.

Four of the cohorts described pregnant women in rural areas [22-24], six in semi-urban areas [3, 22, 31, 34, 35] and twelve in urban areas [21, 23, 25-30, 32, 33]. The studies were also divided into three time periods depending on when participants were recruited - before 2000 [23, 26]; between 2000 and 2009 [21, 22, 28, 32, 35] and from 2010 to 2019 [3, 25, 27, 29-31, 33, 34]. Seven of the cohorts had their deliveries in secondary health facilities $[3,22,31,34,35]$, ten in tertiary hospitals and one in a primary health care facility [24].

The Quality Assessment Tools for observational studies of the National Health Institute/National Heart, Lung, and Blood Institute was used to assess methodological quality. Twelve of the articles were of "good quality" [3, 22, 24-31, 33, 34]; three were of 


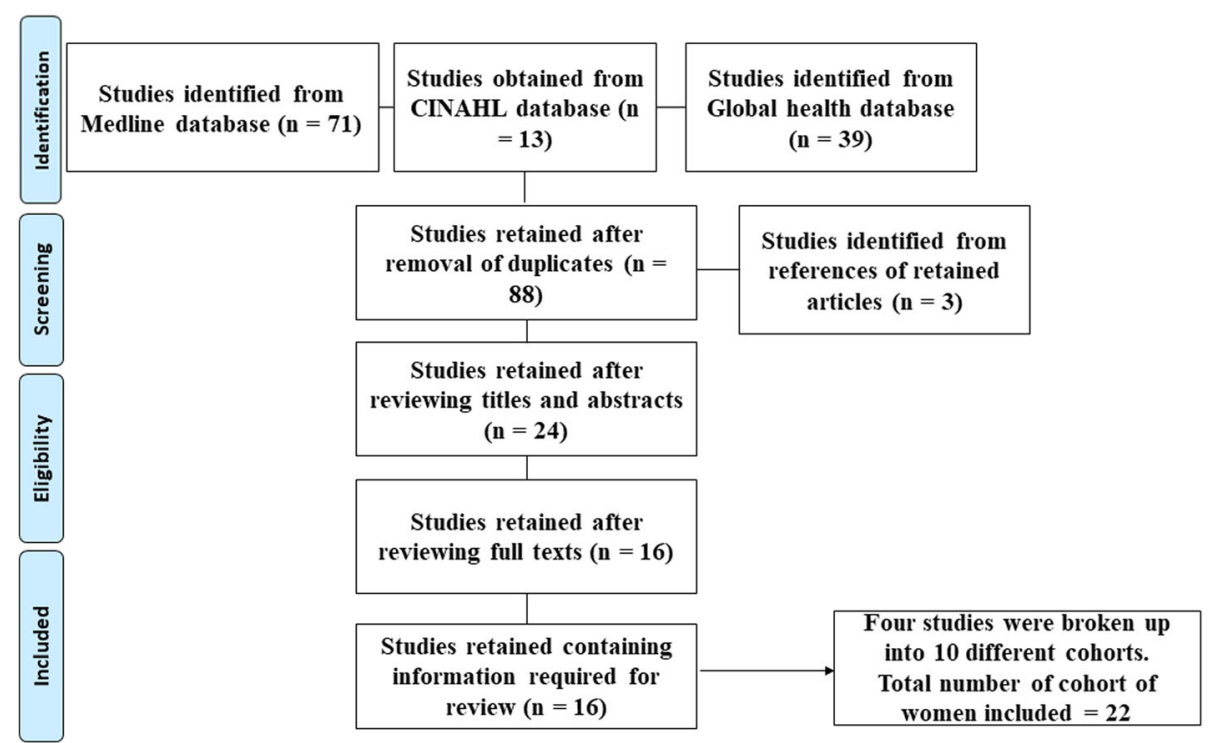

Fig. 1 Flow chart showing inclusion and exclusion of studies in the review

"fair quality" [21, 32, 35] and one was of "poor quality" [23] (Additional file 3).

\section{Prevalence of caesarean deliveries}

The overall estimate for the prevalence of caesarean deliveries in Cameroon was 9.9\% (95\% CI: 7.4, 12.8\%, $\mathrm{I}^{2}=$ 99.68\%, $\left.\chi^{2}=315.9, p<0.001\right)$. Figure 2 shows the pooled prevalence for the various regions in the country. The Centre region had the highest prevalence of caesarean deliveries $17.5 \%$ (95\% CI: 13.8, 21.5\%) while North west region had the lowest prevalence at 3.3\% (95\% CI: 2.6, $4.0 \%)$.

The prevalence of caesarean deliveries increased progressively throughout the time periods from 3.4\% (95\% CI: 2.2, 4.8\%) before the year 2000, to 9.8\% (95\% CI: 7.4, 12.5\%) between 2000 and 2009 and 14.7\% (95\% CI: 8.8, 21.7\%) from 2010 to 2019 (Additional file 4).

The prevalence of caesarean deliveries in rural areas $2.1 \%$ (95\% CI: $1.5,2.7 \%$ ) was lower than that in semiurban areas - 10.8\% (95\% CI: 5.2, 18.2\%) and urban areas $-12.9 \%\left(95 \%\right.$ CI: 9.3, 17.0\%) (overall $\mathrm{I}^{2}=99.8 \%$, $\left.\chi^{2}=10,391.0, p<0.001\right)$ (Additional file 4).

The prevalence of caesarean deliveries in secondary health facilities around the country - 10.1\% (95\% CI: $5.1,16.6 \%)$ was similar to that in tertiary hospitals 15.4\% (95\% CI: $12.5,18.6 \%)$; overall $\mathrm{I}^{2}=99.8 \%, X^{2}=10$, 391.0, $\mathrm{p}<0.001$ (Additional file 4).

\section{Indications of caesarean deliveries in Cameroon}

Seven of the cohorts had data on the various indications of caesarean deliveries [3, 22, 26, 29, 34, 35]. Table 3 shows the various indications of caesarean deliveries and their frequencies as found in each individual study. At least two studies reported a frequency for eight of the indications (Additional file 5): cephalopelvic disproportion (27.5\%; 95\% CI: 17.5, 38.7\%) [3, 22, 26, 29, 34, 35]; previous caesarean section (13.2\%; 95\% CI: 7.4, 20.3\%) [3, 22, 26, 29, 34, 35]; foetal distress (11.2\%; 95\% CI: 4.8, 19.5\%) [3, 22, 26, 29, 34, 35]; malpresentation (9.8\%; 95\% CI: $7.0,12.9 \%)$ [3, 26, 29, 34, 35]; antepartum haemorrhage (8.2\%; $95 \%$ CI: $5.9,10.8 \%)$ [26, 29, 34, 35]; dystocia $(5.9 \%$; 95\% CI: $2.0,11.3 \%$ ) [3, 26, 29, 35]; multiple pregnancies (5.8\%; 95\% CI: 2.0, 11.1\%) [22, 29, 34, 35]; macrosomia (5.7\%; 95\% CI: 3.7, 8.0\%) [22, 29, 34]; cord prolapse (4.0\%; 95\% CI: $1.9,6.8 \%)$ [26, 29, 35]; hypertensive disorders in pregnancy $(3.1 \%$; $95 \%$ CI: $2.1,4.2 \%)[26,34,35]$ and uterine rupture (2.6\%; 95\% CI: 0.6, 5.5\%) [26, 29, 35].

\section{Complications of caesarean deliveries}

Only two studies compared the complications of neonates from caesarean deliveries with neonates from vaginal deliveries [3, 35] (Additional file 6).

Neonates who were born by caesarean delivery were more likely to have neonatal asphyxia when compared with neonates born from vaginal deliveries (OR: 6.5; 95\% CI: $2.5,16.5 ; \mathrm{I}^{2}=0.0 \%, \mathrm{X}^{2}=0.5, p=0.5$ ) while neonates born from a caesarean delivery were just as likely to be stillborn as neonates born from vaginal deliveries (OR: 3.5; 95\% CI: 0.0, 1,348,755.5; $\left.\mathrm{I}^{2}=96.0 \%, \chi^{2}=23.5, p<0.01\right)$.

\section{Conceptual framework}

The conceptual framework summarising the indications and complications of caesarean deliveries in Cameroon is shown in Fig. 3. 


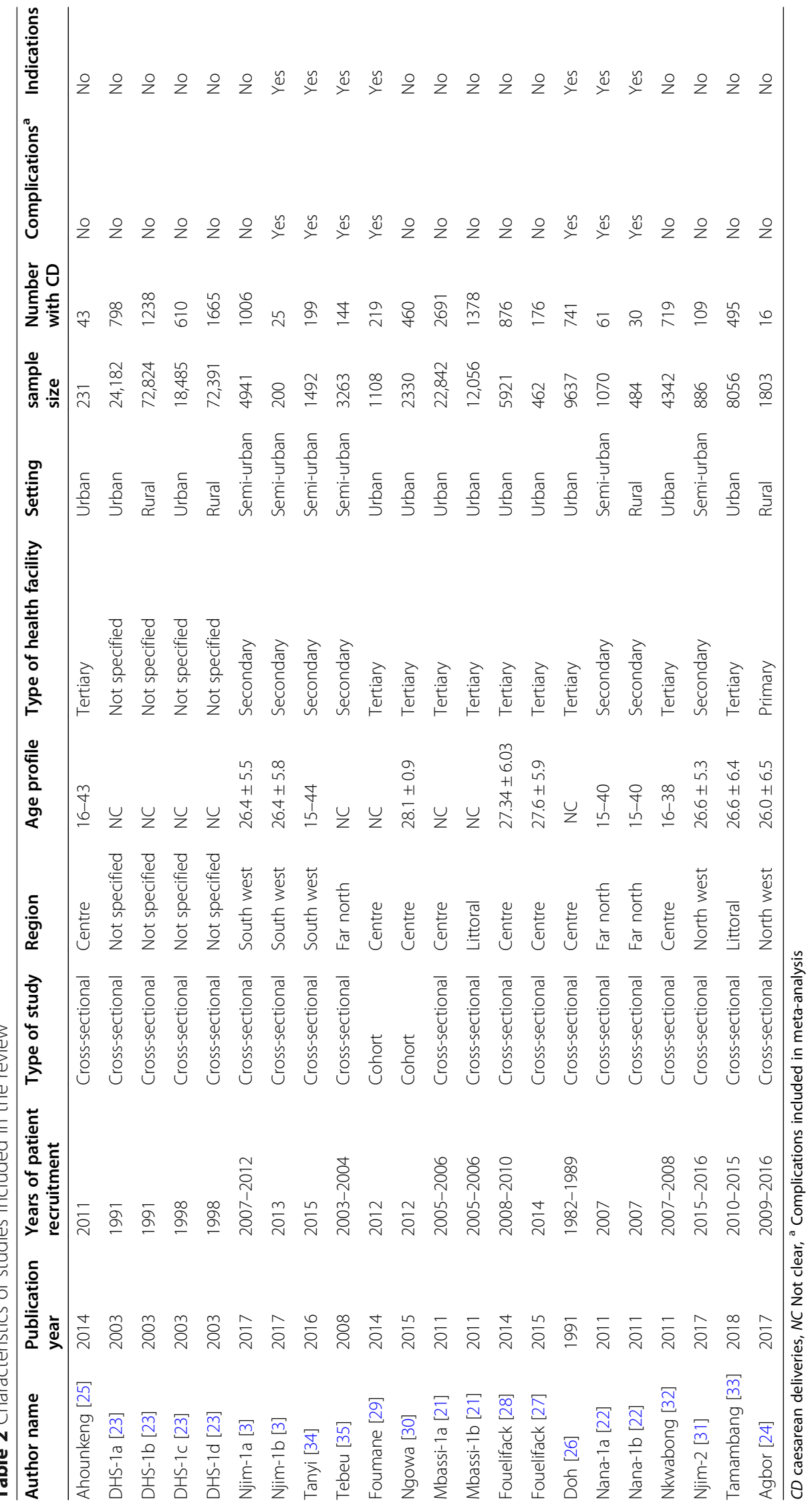




\section{Caesarean Deliveries in Cameroon by various regions}

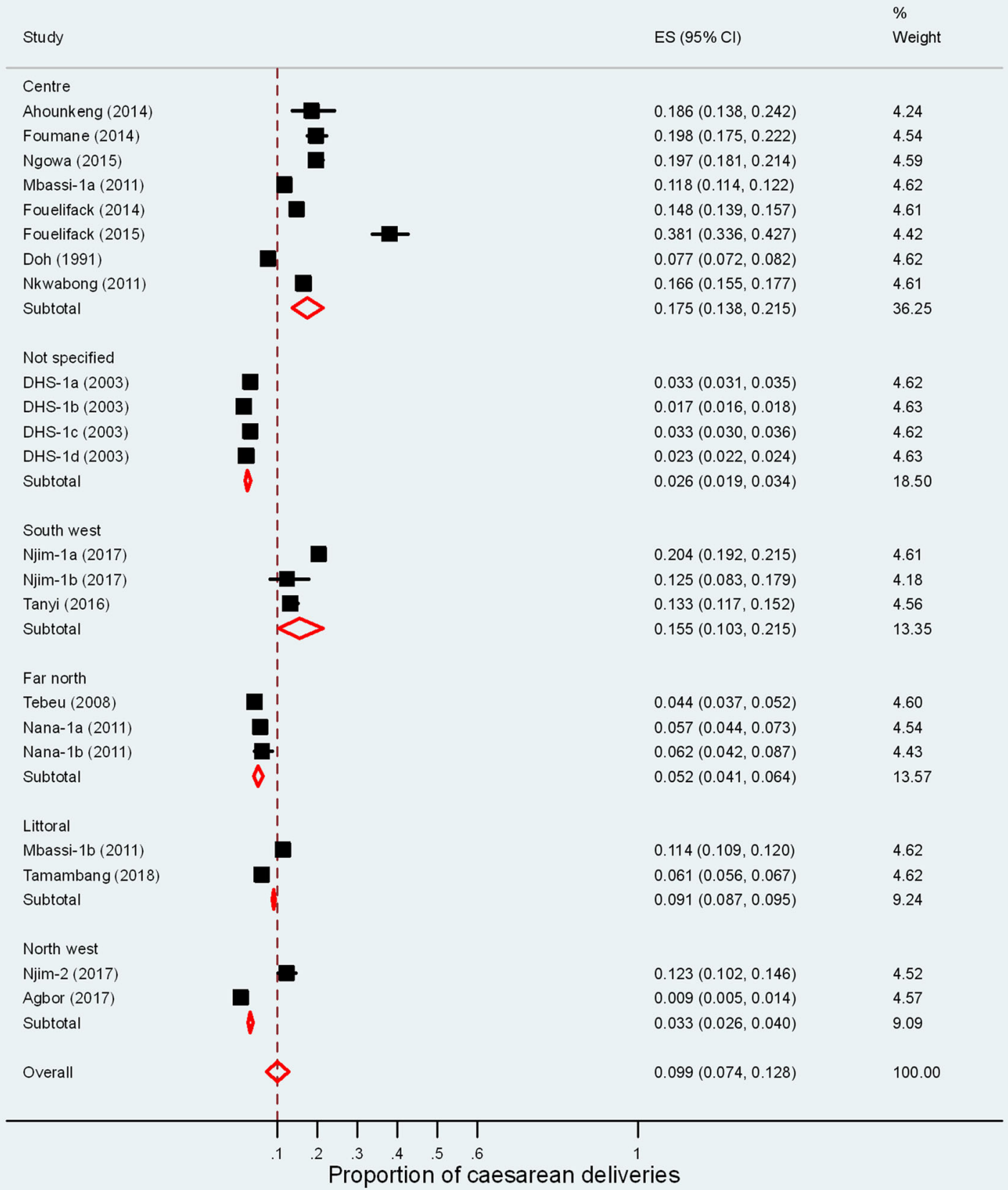

Fig. 2 Meta-analyis of the proportion of caesarean deliveries in Cameroon

\section{Discussion}

In this review, the overall prevalence of caesarean sections in Cameroon was $9.9 \%$. The prevalence ranged from $3.3 \%$ in the North west region to $17.5 \%$ in the centre region and increased progressively over the years from $3.4 \%$ prior to 2000 to $14.7 \%$ after the year 2010. The most common indications of caesarean sections in the country were cephalopelvic disproportion, previous caesarean sections and foetal distress; while neonates who were born by caesarean sections were 
Table 3 Various indications of caesarean deliveries and their relative frequencies as reported in the studies

\begin{tabular}{|c|c|c|}
\hline Author name & sample size $(\mathrm{N})$ & Indications of CD \\
\hline Njim-1b, 2017 [3] & 200 & $\begin{array}{l}\text { Cephalopelvic disproportion (7/25), acute foetal distress (7/25), previous CS (4/25), } \\
\text { malpresentation (3/25), maternal request (3/25), dystocia }(1 / 25)\end{array}$ \\
\hline Tanyi, 2016 [34] & 1492 & $\begin{array}{l}\text { Cephalopelvic disproportion (64/199), previous CS (55), malpresentation (26/199), } \\
\text { foetal distress (16), foetal macrosomia (15), placenta praevia (9), HTN disorders (6), } \\
\text { multiple pregnancy (2), placenta abruption (1) }\end{array}$ \\
\hline Tebeu, 2008 [35] & 3263 & $\begin{array}{l}\text { Cephalopelvic disproportion (47/144), placenta previa (13/144), cord prolapse }(10 / 144) \text {, } \\
\text { uterine rupture }(9 / 144) \text {, arm prolapse }(7 / 144) \text {, malpresentation }(7 / 144) \text {, fibroid previa } \\
\text { (2/144), placenta abruption (2/144), multiple pregnancy }(10 / 144) \text {, dystocia }(6 / 144) \text {, } \\
\text { hypertensive disorders (4/144), previous CS (3/144), malformation (3/144), foetal distress } \\
(2 / 144) \text {, undefined (19/144) }\end{array}$ \\
\hline Foumane, 2014 [29] & 1108 & $\begin{array}{l}\text { Cephalopelvic disproportion (21/219), previous CS (33/219), antepartum haemorrhage } \\
\text { (24/219), malpresentation (20/219), acute foetal distress (18/219), dystocia (28/219), } \\
\text { multiple pregnancy (13/219), macrosomia (11/219), cord prolapse }(9 / 219) \text {, old primipa } \\
\text { (7/219), uterine rupture (4/219), PMTCT (3/219), DVT (2/219) }\end{array}$ \\
\hline Doh, 1991 [26] & 9637 & $\begin{array}{l}\text { Cephalopelvic disproportion (109/741), malpresentation (88/741), foetal distress (159/741), } \\
\text { antepartum haemorrhage (57/741), cord prolapse (19/741), hypertensive disorders (24/741), } \\
\text { uterine rupture (10/741), previous CS (94/741), failed induction/dystocia (29/741), others (152/741) }\end{array}$ \\
\hline Nana-1a, 2011 [22] & 1070 & $\begin{array}{l}\text { Cephalopelvic disproportion }(28 / 61) \text {, foetal distress }(7 / 61) \text {, multiple pregnancy }(9 / 61) \text {, } \\
\text { previous CS }(8 / 61) \text {, macrosomia }(2 / 61) \text {, others }(7 / 61)\end{array}$ \\
\hline Nana-1b, 2011 [22] & 484 & $\begin{array}{l}\text { Cephalopelvic disproportion }(13 / 30) \text {, foetal distress }(4 / 40) \text {, multiple pregnancy }(2 / 30) \text {, } \\
\text { previous CS }(4 / 30) \text {, others }(7 / 30)\end{array}$ \\
\hline
\end{tabular}

$N$ total number of pregnant women, HTN hypertension, CS caesarean section, PMTCT prevention of mother to child transmission, DVT deep vein thrombosis

significantly more likely to have neonatal asphyxia at birth.

From the pooled overall prevalence (and 95\% confidence limits) of caesarean deliveries in Cameroon, it seems to fall just within the recommended WHO range of $10-15 \%[4,5]$. Some regions like the North west region $(3.3 \%)$ and the Far north region $(5.2 \%)$ fell well below this range. Other regions like the South west region $(15.5 \%)$ were just within the target while the prevalence was much higher in the centre region (17.5\%).
This could be explained by the fact that the Centre region has more tertiary health facilities than the other regions in the country (Additional file 1). The tertiary health facilities in the country are at the top of the referral chain and hence carry out more emergency procedures (caesarean sections inclusive) than the secondary and primary health facilities. Indeed, our review showed that tertiary health facilities carried out more caesarean sections $(15.4 \%)$ than secondary health facilities (10.1\%). This assertion is supported by the study carried out by

INDICATIONS OF CAESAREAN DELIVERIES IN CAMEROON

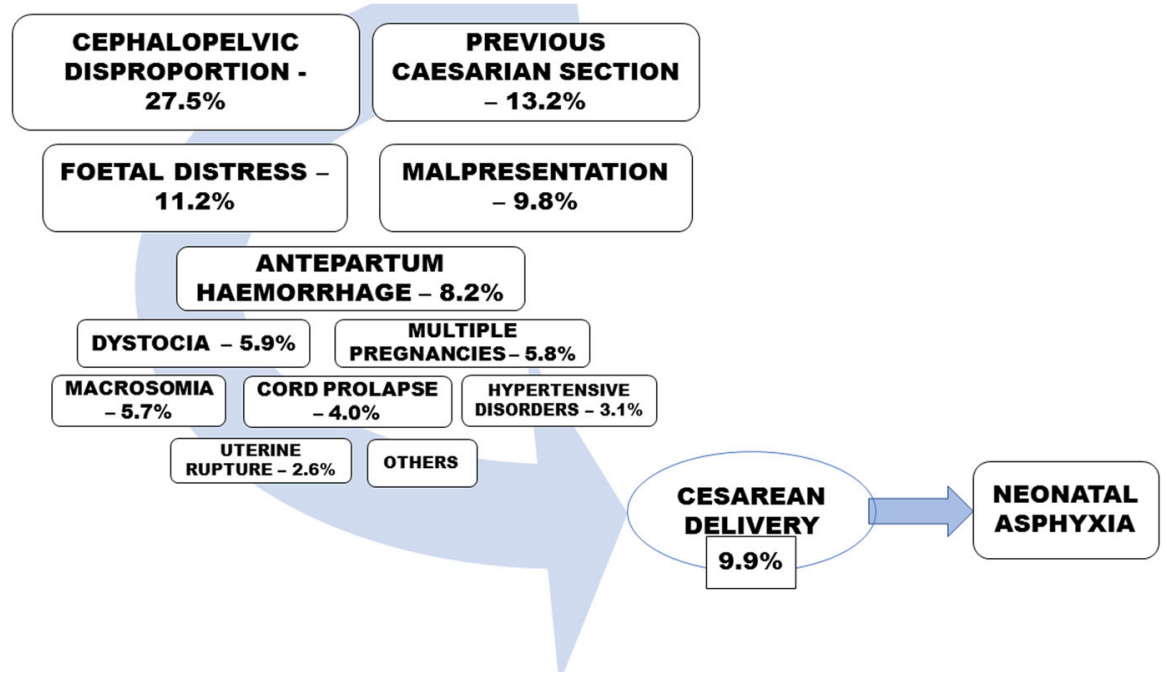

Fig. 3 Conceptual framework of the indications and complications of caesarean deliveries in Cameroon 
Agbor et al in primary health facilities of a rural area of the North west region of Cameroon where the low rates of caesarean deliveries $(0.9 \%)$ were explained by the absence of a permanent doctor in these facilities [24].

The rates of caesarean sections in Cameroon were however lower when compared with other countries in Africa like Ethiopia (27.6\%), Libya (23.5\%) and Rwanda (64.2\%) [36-38]. The rates were also lower than those in Asian and Middle-eastern countries: Pakistan (24.1\%), Iran (48\%), India (13.7-37.9\%) [39-41]; South America: Brazil (55.5\%) [42] and Europe: Cyprus (52.2\%) and Iceland (14.8\%) [43]. These high caesarean section rates are ever increasing worldwide [3, 10], even in subSaharan African countries [3, 14]. This trend was also shown to be true in Cameroon as demonstrated in this review. The prevalence of caesarean deliveries increased from $3.4 \%$ before the year 2000 , to $9.8 \%$ between 2000 and 2009 and $14.7 \%$ from 2010 to 2019 . With this trend, it could be estimated that the rates of caesarean deliveries in Cameroon will soon surpass the WHO recommended range. This therefore points to the need for investigations into factors driving this trend and harmonisation of obstetric care around the country.

The three main indications of caesarean deliveries seen in this review were cephalopelvic disproportion, a previous caesarean section and foetal distress. The above indications were found to be the commonest indications for caesarean births in Ethiopia [36]. These three indications were also found to be in the top five commonest medical factors driving the decision in performing a caesarean section in a review performed in India [40]. The authors showed that previous caesarean sections, foetal distress, failure of labour progression, cephalopelvic disproportion, maternal disease and abnormal presentation were the most common causes of caesarean deliveries [40]. Similarly, in Pakistan, Najmi et al determined that repeat caesarean section and foetal distress were amongst the commonest indications for caesarean deliveries in a tertiary hospital [39]. Considering that these indications are universal, this could be useful information for healthcare providers especially in rural areas in Cameroon where caesarean sections are not routinely performed [24]. Women presenting with the following indications at delivery should be considered as high-risk deliveries and referred appropriately to services where caesarean sections could easily be performed. This could help to reduce maternal and perinatal mortality and morbidity associated with childbirth in the country.

In this review, neonates who were born by caesarean delivery were also more likely to have neonatal asphyxia when compared with neonates who were born through vaginal deliveries. Considering that most of the indications of caesarean sections obtained in this review foetal distress, dystocia, cord prolapse and antepartum haemorrhage; include obstruction of blood and oxygen supply to the foetus, it is therefore conceivable that neonates who are born through caesarean sections will be more likely to have asphyxia at birth. Also, in Cameroon, most cases requiring obstetrical care are first received at the primary health care facilities. These facilities generally lack both the technical plateau and skilled human resources needed to diagnose the aforementioned complications or perform caesarean deliveries [24]. They therefore end up being referred to facilities higher up the referral chain. However, with the poor distribution of tertiary hospitals around the country, a lot of time is used up to cover significant distances needed to get to these referral centres. Consequently, patients arrive and are managed in an emergency setting. Emergency caesarean deliveries have been shown to be associated with poor perinatal outcome [44].

This highlights the need for delivery services in healthcare facilities around the country to be equipped with both skilled personnel and the necessary resources to diagnose and manage these conditions and perform caesarean sections. Likewise, centres where caesarean deliveries are performed, and physicians, should be ready to anticipate birth asphyxia as a possible caesarean delivery outcome and prepare guidelines and management plans accordingly.

We would like to note some of the limitations of this review. First, five regions in the country did not have separate data providing the rates of caesarean sections in this region. The overall estimate provided in this review may therefore underestimate or overestimate the prevalence of caesarean sections. However, the DHS studies included in the review draw from approximately all the regions in the country and could help limit this bias. Secondly, the two studies that measured the association between neonatal asphyxia and caesarean deliveries used the Apgar scores to diagnose asphyxia. The Apgar score is not the gold standard for the diagnosis of asphyxia. It could however be used to assess the probability of a neonate to have asphyxia especially in settings where diagnostic apparatus is limited like in rural and semi-urban health facilities in Cameroon. Thirdly, there was a high degree of heterogeneity seen in some of the metaanalyses. We speculate that this may be due to the different periods of participant recruitment, settings, study designs, number of studies in the review and health facilities used in the various studies. There was significant heterogeneity between the subgroups and the number of studies in each subgroup were not large enough to draw conclusive results. Caution should therefore be used when interpreting the meta-analysis in this review.

\section{Conclusion}

The rates of caesarean deliveries in Cameroon falls just within the recommended $10-15 \%$ range proposed by the 
WHO. The rates in rural and sub-urban settings in the country fall far below this range due to lack of adequate facilities and healthcare personnel required to carry out these surgeries. There is a strong need to recruit healthcare personnel capable of carrying out these deliveries in areas that are lacking and reinforcing the current workforce in hospitals that are already carrying out caesarean deliveries. Also, the commonest indications and complications of caesarean deliveries should be anticipated in women of childbearing age to improve management plans and guidelines and decrease the associated maternal and foetal morbidity and mortality.

\section{Supplementary information}

Supplementary information accompanies this paper at https://doi.org/10. 1186/s13690-020-00430-1.

\section{Additional file 1. \\ Additional file 2. \\ Additional file 3. \\ Additional file 4. \\ Additional file 5 . \\ Additional file 6 .}

\section{Abbreviations}

OR: Odds ratio; PRISMA: Preferred Reporting Items for Systematic Reviews and Meta-Analyses

\section{Acknowledgements}

Special thanks to Dr. Tinevimbo Shiri for proofreading the work.

\section{Authors' contributions}

Study conception and design: TN; screening of articles: TN \& BST; writing of initial manuscript: TN; review of literature: TN \& CM; review of manuscript:

TN, BST \& CM. The author(s) read and approved the final manuscript.

\section{Funding}

None.

\section{Availability of data and materials \\ Not applicable.}

\section{Ethics approval and consent to participate}

Not applicable.

\section{Consent for publication}

Not applicable.

\section{Competing interests}

Authors declare no conflicts of interest relevant to this article.

\begin{abstract}
Author details
${ }^{1}$ Health and Human Development (2HD) Research Group, Douala, Littoral region, Cameroon. ${ }^{2}$ Higher Institute of Commerce and Management, University of Bamenda, Bamenda, North west region, Cameroon. ${ }^{3}$ Mankon Sub-divisional Hospital, Bamenda, North west region, Cameroon.
\end{abstract}

Received: 12 August 2019 Accepted: 14 May 2020

Published online: 03 June 2020

\section{References}

1. WHO HRP. WHO statement on caesarean section rates: every effort should be made to provide caesarean sections to women in need, rather than striving to achieve a specific rate; 2015.
2. Guzman E, Ludmir J, DeFrancesco M. High cesarean section rates in Latin America, a reflection of a different approach to labor? Open J Obstet Gynecol. 2015;5:433-5.

3. Njim T, Choukem SP, Mbu R. Cesarean sections in a secondary level care hospital of Cameroon: an analysis of their six-year trends and adverse neonatal outcomes. BMC Res Notes. 2017;10(1):430.

4. Chalmers B. WHO appropriate technology for birth revisited. Br J Obstet Gynaecol. 1992;99(9):709-10.

5. Appropriate technology following birth. Lancet. 1986;2(8520):1387-8.

6. Betran AP, Torloni MR, Zhang J, Ye J, Mikolajczyk R, Deneux-Tharaux C, et al. What is the optimal rate of caesarean section at population level? A systematic review of ecologic studies. Reprod Health. 2015;12:57.

7. Hannah ME, Hannah WJ, Hewson SA, Hodnett ED, Saigal S, Willan AR. Planned caesarean section versus planned vaginal birth for breech presentation at term: a randomised multicentre trial. Term Breech Trial Collaborative Group. Lancet. 2000;356(9239):1375-83.

8. Ye J, Betran AP, Guerrero Vela M, Souza JP, Zhang J. Searching for the optimal rate of medically necessary cesarean delivery. Birth. 2014;41(3):237-44.

9. Althabe F, Sosa C, Belizan JM, Gibbons L, Jacquerioz F, Bergel E. Cesarean section rates and maternal and neonatal mortality in low-, medium-, and high-income countries: an ecological study. Birth. 2006;33(4):270-7.

10. Keag OE, Norman JE, Stock SJ. Long-term risks and benefits associated with cesarean delivery for mother, baby, and subsequent pregnancies: systematic review and meta-analysis. PLoS Med. 2018;15(1):e1002494.

11. Prediger B, Polus S, Mathes T, Buhn S, Louwen F, Neugebauer EAM, et al. (Update of a) systematic review on the impact of elective early term $(<$ 39th gestational week) caesarean sections on maternal and neonatal health - a protocol. Syst Rev. 2018;7(1):119.

12. Betran AP, Merialdi M, Lauer JA, Bing-Shun W, Thomas J, Van Look P, et al. Rates of caesarean section: analysis of global, regional and national estimates. Paediatr Perinat Epidemiol. 2007;21 (2):98-113.

13. McCourt C, Weaver J, Statham H, Beake S, Gamble J, Creedy DK. Elective cesarean section and decision making: a critical review of the literature. Birth. 2007:34(1):65-79.

14. Geidam AD, Audu BM, Kawuwa BM, Obed JY. Rising trend and indications of caesarean section at the university of Maiduguri teaching hospital, Nigeria. Ann Afr Med. 2009;8(2):127-32.

15. Lumbiganon P, Laopaiboon M, Gulmezoglu AM, Souza JP, Taneepanichskul $\mathrm{S}$, Ruyan $\mathrm{P}$, et al. Method of delivery and pregnancy outcomes in Asia: the WHO global survey on maternal and perinatal health 2007-08. Lancet. 2010; 375(9713):490-9.

16. Villar J, Carroli G, Zavaleta N, Donner A, Wojdyla D, Faundes A, et al. Maternal and neonatal individual risks and benefits associated with caesarean delivery: multicentre prospective study. BMJ. 2007;335(7628):1025.

17. Souza JP, Gulmezoglu A, Lumbiganon P, Laopaiboon M, Carroli G, Fawole B, et al. Caesarean section without medical indications is associated with an increased risk of adverse short-term maternal outcomes: the 2004-2008 WHO global survey on maternal and perinatal health. BMC Med. 2010;8:71.

18. The World Bank. The World Bank in Cameroon Cameroon 2017. Access Date: 30 July 2019. Available from: https://www.worldbank.org/en/country/ cameroon/overview.

19. Index Mundi. Cameroon Urbanization 2018 updated 20/01/2018. Access Date: 30 July 2019. Available from: https://www.indexmundi.com/ Cameroon/urbanization.html.

20. Cameroon Population 2019. Access Date: 30 July 2019. Available from: http://worldpopulationreview.com/countries/cameroon-population/ \#popDensityMap.

21. Mbassi SM, Mbu R, Bouvier-Colle MH. Use of routinely collected data to assess maternal mortality in seven tertiary maternity centers in Cameroon. Int J Gynaecol Obstet. 2011;115(3):240-3.

22. Nana PN, Fomulu JN, Djenabou A, Mbu RE, Tonye R, Wandji JC, et al. Epidemio-clinical factors associated with caesarean section in two referral hospitals (public/faith-based), Far-North region, Cameroon. Clin Mother Child Health. 2011;8:Article ID C100602-Article ID C.

23. Buekens P, Curtis S, Alayón S. Demographic and Health Surveys: caesarean section rates in sub-Saharan Africa. Br Med J. 2003;326(7381):136.

24. Agbor VN, Mbanga CM, Njim T. Adolescent deliveries in rural Cameroon: an 8 -year trend, prevalence and adverse maternofoetal outcomes. Reprod Health. 2017;14(1):122.

25. Ahounkeng NP, Mboudou ET, Adjoby CR, Rakotomalala NZ, Foumane $\mathrm{P}$, Dohbit SJ, et al. Impact of excessive weight gain during pregnancy on 
maternal and fetal outcome at the Yaoundé Women's and Children's hospital (Cameroon). Medecine Et Sante Tropicales. 2014;24(1):63-7.

26. Doh AS. A clinical study of caesarean section at the university teaching hospital (C.H.U.) Yaounde (1982-1989). Cent Afr J Med. 1991;37(10):326-8.

27. Fouelifack FY, Fouedjio JH, Fouogue JT, Sando Z, Fouelifa LD, Mbu RE. Associations of body mass index and gestational weight gain with term pregnancy outcomes in urban Cameroon: a retrospective cohort study in a tertiary hospital. BMC Research Notes. 2015;8:806.

28. Fouelifack FY, Tameh TY, Mbong EN, Nana PN, Fouedjio JH, Fouogue JT, et al. Outcome of deliveries among adolescent girls at the Yaoundé central hospital. BMC Pregnancy Childbirth. 2014;14:102.

29. Foumane P, Mve Koh V, Ze Minkande J, Njofang Ngantcha EA, Dohbit JS, Mboudou ET. Risk factors and prognosis of emergency cesarean delivery at the Yaoundé Women's and Children's hospital, Cameroon. Medecine Et Sante Tropicales. 2014;24(1):89-93.

30. Ngowa JDK, Ngassam A, Fouogue JT, Metogo J, Medou A, Kasia JM. Early maternal complications of caesarean section: Review of 460 cases in two university hospitals in Yaounde, Cameroon. / Complications maternelles précoces de la césarienne: à propos de 460 cas dans deux hôpitaux universitaires de yaoundé, Cameroun. Pan Afr Med J. 2015;21:265.

31. Njim T, Agbor VN. Adolescent deliveries in semi-urban Cameroon: prevalence and adverse neonatal outcomes. BMC Res Notes. 2017;10(1):227.

32. Nkwabong E, Nana PN, Mbu R, Takang W, Ekono MR, Kouam L. Indications and maternofetal outcome of instrumental deliveries at the university teaching Hospital of Yaounde, Cameroon. Tropical Doctor. 2011;41(1):5-7.

33. Tamambang RF, Njim T, Njie AE, Mbuagbaw L, Mafuta A, Tchana M, et al. Adolescent deliveries in urban Cameroon: a retrospective analysis of the prevalence, 6-year trend and adverse outcomes. BMC Res Notes. 2018;11(1):469.

34. Tanyi TJ, Atashili J, Fon PN, Robert T, Paul KN. Caesarean delivery in the Limbé and the Buea regional hospitals, Cameroon: frequency, indications and outcomes. Pan Afr Med J. 2016;24:227.

35. Tebeu PM, Ngassa P, Mboudou E, Kongnyuy E, Binam F, Abena MTO. Neonatal survival following cesarean delivery in northern Cameroon. Int J Gynaecol Obstet. 2008;103(3):259-60.

36. Moges A, Ademe BW, Akessa GM. Prevalence and Outcome of Caesarean Section in Attat Hospital, Gurage Zone, SNNPR, Ethiopia. Arch Med. 2015; 7(4):8.

37. Elzahaf RA, Ajroud S. Prevalence and indication of cesarean section in AlWahda hospital, Derna, Libya: a retrospective study. Libyan J Med Sci. 2018; 2(2):68-72.

38. Yaya S, Uthman OA, Amouzou A, Bishwajit G. Disparities in caesarean section prevalence and determinants across sub-Saharan Africa countries. Glob Health Res Policy. 2018;3:19.

39. Najmi RS, Rehan N. Prevalence and determinants of caesarean section in a teaching hospital of Pakistan. J Obstet Gynaecol. 2009;20(5):479-83.

40. Rafiei M, Saei Ghare M, Akbari M, Kiani F, Sayehmiri F, Sayehmiri K, et al. Prevalence, causes, and complications of cesarean delivery in Iran: a systematic review and meta-analysis. Int J Reprod Biomed (Yazd). 2018;16(4): 221-34

41. Singh P, Hashmi G, Swain PK. High prevalence of cesarean section births in private sector health facilities- analysis of district level household survey-4 (DLHS-4) of India. BMC Public Health. 2018;18(1):613.

42. Barros FC, Rabello Neto DL, Villar J, Kennedy SH, Silveira MF, Diaz-Rossello $\mathrm{J}$, et al. Caesarean sections and the prevalence of preterm and early-term births in Brazil: secondary analyses of national birth registration. BMJ Open. 2018;8(8):e021538.

43. Wise J, et al. BMJ. 2015:350:h1812

44. Benzouina S, Boubkraoui Mel M, Mrabet M, Chahid N, Kharbach A, ElHassani A, et al. Fetal outcome in emergency versus elective cesarean sections at Souissi maternity hospital, Rabat, Morocco. Pan Afr Med J. 2016; 23:197.

\section{Publisher's Note}

Springer Nature remains neutral with regard to jurisdictional claims in published maps and institutional affiliations.

Ready to submit your research? Choose BMC and benefit from:

- fast, convenient online submission

- thorough peer review by experienced researchers in your field

- rapid publication on acceptance

- support for research data, including large and complex data types

- gold Open Access which fosters wider collaboration and increased citations

- maximum visibility for your research: over $100 \mathrm{M}$ website views per year

At $\mathrm{BMC}$, research is always in progress.

Learn more biomedcentral.com/submissions 